\title{
Blok Zincir ile Web Tabanlı Anket Uygulaması
}

\author{
Hüseyin ASILTÜRK (iD ${ }^{*}$, Ali Hakan IŞIK (iD) \\ ${ }^{1}$ Burdur Mehmet Akif Ersoy Üniversitesi, Mühendislik Mimarlık Fakültesi, Burdur \\ Geliş Tarihi (Received): 07.10.2021, Kabul Tarihi (Accepted): 13.12.2021 \\ $\square$ Sorumlu Yazar (Corresponding author*): huseyinasilturk@outlook.com \\ (C) +902482132750 且 +902482132704
}

\section{$\overline{O ̈ Z}$}

Covid-19 pandemisi ile birçok gereksinimler uzaktan ve sosyal mesafe kurallarına göre gerçekleştirmektedir. Bu kurallar, eğitim, iş, market alışverişi gibi birçok alanda uygulanmaktadır. Anket veya oy kullanmada bu süreçte zamanla zorunlu hale gelebilecektir. Günümüzde anketlerin çoğu elektronik sistemler üzerinden gerçekleştirilmektedir. Kullanıcılar, oluşturulan anketleri paylaşarak hiçbir temasta bulunmadan fikir alışverişi yapabilmektedir. Çalışmada bir anket sistemi oluşturulmuştur. Bu çalışmada asıl amaç ise anket kayıtları blok zincir altyapısı kullanan etheryum ağında oluşturulan akıllı kontrat üzerine kaydedilerek kayıtların ileri seviyede güvenliği sağlanmasıdır. Çalışmada kullanıcı verilerinin güvenliği ön planda tutulurken kullanım kolaylığı da sağlanmaktadır. Çalışmada, web ara yüzleri için Web3.js, Bootstrap ve MVC teknolojileri kullanılmıştır. Akışı sağlamak için veri kaydı iki alana yapılmaktadır. Bunlardan ilki etheryum tabanlı akıllı kontrat diğeri MySQL veri tabanıdır. Kullanıcı verileri ilk olarak blok ağına kayıt talebinde bulunmaktadır. Bu sürede, kullanıcının kaydı ağa kaydedilinceye kadar beklememesi için veriler MySQL veri tabanına da kaydedilmektedir. Böylelikle kullanıc beklemek zorunda kalmamakta ve işlemlerine devam edebilmektedir. Kullanıcı sistemden verilerinin kontrolünü yapmak istediğinde kontrol modülünden etheryum test ağındaki veri ile MySQL verisini karşılaştırması istenmektedir. Karşılaştırma sonrası bir sorun olması durumunda profil anahtarı ile yöneticiye başvurulmakta ve tam güvenlik sağlayan blok zincir ağındaki kayıt doğru kabul edilmektedir. Çalışma, ankette bulunan kullanıcı verilerinin güvenliğini üst seviye de sağlaması ile literatüre katkı sağlamaktadır.

Anahtar Kelimeler: Akıllı kontrat, anket, blok zincir, etheryum, güvenlik

\section{Web Based Survey Application with Blockchain}

\begin{abstract}
With the Covid-19 pandemic, many requirements are carried out according to distance and social distance rules. These rules are applied in many areas such as education, work, market shopping. Polling or voting may also become mandatory in this process. Today, most of the surveys are carried out through electronic systems. Users can exchange own ideas without any contact with the created surveys. A survey system was created in our study. In the study, advanced security of the survey records was ensured by storing the data on the smart contract that is created in the ethereum network using the blockchain infrastructure. In the study, while ensuring the security of user data, ease of use was also provided. Web3.js, Bootstrap and MVC technologies were also used for web interfaces in the study. Data recording was done in two fields to ensure flow. One of them is ethereum-based smart contract and the other is MySQL database. User data first requests registration to the block network. During this time, the data is saved in the MySQL database so that the user does not wait until the record is registered in the network. Thus, the user does not have to wait and can continue with his transactions. When the user wants to control his data from the system, the control module is requested to compare the data in the ethereum test network with the MySQL data. If there is a problem after the comparison, the administrator checked the profile key and the record in the blockchain network,
\end{abstract}


which provides full security, was accepted as correct. The study contributes to the literature by providing the highest level of security for the user data in the survey.

Keywords: Smart contract, survey, blockchain, ethereum, security

\section{Giriş}

Her geçen gün teknoloji bir öncesine göre kat kat büyümekte ve sürekli de büyümeye devam etmektedir. Gelişen teknoloji ile de yaşantımızdaki birçok şey değişmektedir. Bununla beraber tüm dünyayı etkisi altına alan Covid-19 pandemisi de bu süreci hızlandırmıştır. Covid-19 pandemi sürecinde bilgi iletişim teknolojileri insanlar için "kurtarıcı" olarak nitelendirilebilmektedir (Gökler ve ark., 2020). Market alışverişinden eğitim öğretim hayatımıza kadar her şey teknoloji kapsamında çözümlenmektedir. Tüm bunları düşündüğümüz de oylama sistemleri de artık teknolojiye ayak uydurmaktadır. Fakat oylama ve anket gibi sistemlerde güvenlik her zaman daha ön planda olmuştur. E-oylama sistemleri günümüz kâğıt üzerinde yapılan oylamaların zorluklarına çözüm olarak önerilmiştir (Daramola ve Thebus, 2020). Hız, güvenilirlik ve kullanılabilirlik oylama sistemlerinin en temel taşlarıdır. Bu sistemlerin güvenlik sorunları için ise ayrıntılı bir inceleme gerçekleştirilmiştir (Ryan ve ark., 2015). Teknolojiyi kullandığımız tüm alanları düşününce neden oylama sistemini de uzaktan yapmayalım sorusunu akıllara getirmektedir. Tabi teknolojiyi kullanmak her zaman bizi daha ileriye götürse de her yeniliğin arkasından bir acaba korkusu bizleri tetiklemektedir. Çalışmanın da yer aldığı bu konu için korkuların başlıca nedenleri hız, güvenilirlik ve kullanılabilirliğin sağlanabiliyor olduğundan emin olmamaktır. Blok zincir yapısı sayesinde artık güvenlik endişesi neredeyse tamamen ortadan kalkmaktadır. Her ne kadar blok zincir yapısı ilk olarak bitcoin ve benzeri maddi değer biçilen birimler için altyapı oluştursa bile günümüzde finans, sağlık ve telekomünikasyon gibi birçok alanda kullanılma potansiyeli bulunmaktadır (Kırbaş, 2018). Bazı ülkelerde ulusal seçimlerin de blok zincir üzerinden yapılması önerilmiştir. Bu ülkeler arasında Güney Kore, Hindistan ve Estonya yer almaktadır (Bulut ve ark., 2019). Çalışmada blok zincir ile anket sistemlerinin eksiklik ve sorunlarına çözüm aranmaktadır.

Yapılan literatür taramasında bazı çalışmalara rastlanmıştır. Treleaven ve ark. (2017), blok zincirin finans alanındaki büyük etkilerine ve uygulama zorluklarına çalışmalarında yer vermişlerdir. Belchior ve ark. (2022), blok zinciri destekleyen teknolojiler ile daha aktif ve güçlü bir yapı kurulabileceğine değinmişlerdir. Bu yapıların kullanılabilirliği ve zorlukları üzerine bir çaIışma gerçekleştirilmiştir. Gürfidan ve Akçay (2020), blok zincir temelini kullanarak güvenli bir oylama sistemi üzerine çalışma yürütmüşlerdir. Çalışmalarında C\# programlama dilini kullanan Gürfidan ve Akçay (2020), blok zincirin öneminden ve bu sistemlerde kullanılmasının getireceği avantajlardan bahsetmişlerdir. Lin ve Liao (2017) çalışmalarında, etheryum ağından ve onunla oluşturulan akıllı kontratlardan bahsetmişlerdir. Wank ve ark. (2019), gelecek için önemli bir kavram olan nesnelerin interneti için verilerin öneminden bahsetmiştir. Bu verilerin saklanmasında bulut sistemlerinin güvenli olmayacağı ve sorunlara neden olacağına değinilmiş. Bu güvenlik sorununu bozulmaya ve değiştirilmeye dayanıklı olan blok zincir tabanlı veri saklama yönteminin kullanılabileceğine değinmişlerdir. Zhang ve ark. (2017), blok zincirin tutarlı, bozulamaz ve güvenli yapısının üstünlüğünü sağlık uygulamalarında da kullanılabileceğinden bahsetmişlerdir. Örnek sağlık uygulamalarını incelemişler ve yapılarına örnek vermişler. Bir diğer sağlık alanında inceleme yapan çaIışma ise Kıyak ve ark. (2019) tarafından gerçekleştirilmiş. Bu çalışmada üç farklı blok zincir kullanan sağlık uygulamasına yer vermişlerdir. Tijan ve ark. (2019), blok zincir teknolojisinin lojistik sektöründe mal hasarı, taşımacılık, sipariş gecikmesi ve çoklu veri girişi gibi alanlar nası öncülük yapabileceğine değinilmiş. Bir diğer lojistik alanında çalışa yürüten Tekin ve ark. (2020), blok zincir ve akıllı lojistik uygulamalarından bahsetmişlerdir. Bu uygulamaların birbirlerine olan faydaları ve katkıları üzerine durmuşlar, blok zincirin lojistik çalışmalarına olan katkılarından bahsetmişlerdir. Onay ve ark. (2019) çalışmalarında, bir tedarik zinciri oluşturmuşlardır. Bu tedarik zinciri sisteminde kargo firması satıcı ve alıcı arasında bir kontrat oluşturularak güvenlik sağlanmaya çalışılmıştır. Özdoğan ve Karğın (2018) çalışmalarında, finansa ve muhasebe alanlarında blok zincir yapısının kullanım alanlarını incelenmiş ve sapladığı avantaj ve dezavantajlarından bahsedilmiştir. Bu çalışmaların tamamına bakıldığında ise blok zincir yapısının birçok sektör ve alanda aktif olarak kullanılabileceğini gözlemlenmiştir.

Çalışmada kullanılan blok zincir merkezli bitcoin, merkezi otoriteden bağımsız, dağıtık yapıda bulunan dijital para birimi olarak finans dünyasında adından çokça bahsettirmektedir (Kızıltepe ve Öz, 2016). Bir başka 
değişle, bitcoin tüm verilerini birçok birbirine bağlı bloklarda saklayarak güvenli bir yapı sağlamaktadır. Bir veri tabanının birçok bilgisayarda tutulması gibi düşünülebilir. Bir veri başkası tarafından değiştirildiği zaman diğer düğümler (node) tarafından kontrol edilmekte ve düğümler üzerindeki çoğunluk verinin ne olduğunu söylüyorsa o doğru kabul edilmektedir. Böylelikle veri güvenli merkezi bir sisteme değil dağıtık bir şekilde tüm düğümler üzerinde tutulmaktadır. Bu sisteme aslında blok zincir denilmektedir. Blok zinciri bir başka deyişle bağlı liste denilebilmektedir (Kızıltepe ve ark., 2016). Uygulama, blok zincir altyapısı kullanan etheryum ağında özel bir kontrat üzerinden işlem görmektedir. Tüm veriler bu kontratta saklanmakta ve bir sorun ile karşı karşıya olduğunu düşünen kullanıcı burada tam güvenlikli verilerini kontrol edebilmektedir. Her teknolojinin artıları ve eksileri bulunmaktadır. Blok zincirin eksisi için de yavaşılı diyebiliriz. Güvenli, şeffaf ve erişilebilir olan blok zincir olası arızalar ve siber saldırılara karşıda büyük bir güven sağlamaktadır fakat yavaş ve hantal olması sebebi ile birçok alan için kullanımı uygun görülmemektedir (Büyükakın, 2019). Tüm cevapları sıralı bir şekilde kaydetmek sistemin yavaşlamasına sebep olmaktadır. Bu yavaşlığı gidermek ve kullanıcıya daha hızlı bir deneyim sağlamak amacıyla çalışmada cevaplar veri tabanına kaydedilmektedir. Güvenliği sağlamak için ise aynı cevaplar etheryum ağını kullanan akıllı kontrata eş zamanlı olarak kaydedilmektedir. Verdiği cevabın değiştirildiğini düşünen kullanıcı verilerini kontrol et butonu ile değiştirilip değiştirilmediğine kısa sürede emin olabilmektedir. Çalışmada böylelikle hem kullanıcıya hız hem güven sağlamaktadır. Çalışma, günümüzde anket ve oylama sistemlerinin karşılayabileceği birçok özelliği karşılamaktadır.

\section{MATERYAL VE YÖNTEM}

Bu bölümde çalışmada kullanılabilir, tüm platformlara uyumlu ve güvenli kılan teknolojilerine değinilmiştir. Özellikle çalışmayı diğer çalışmalardan ayıran blok zincir yapısından ve bu yapıyı kullanmak için çoklu dil iletişimi sağlayan web3.js yapısından bahsedilecektir. Güvenliği çalışmaya eklemek için gerekli olan etheryum kontratları ve bu kontratlar için gerekli olan cüzdan yapısını sağlayan MetaMask uygulaması da kısaca açıklanmıştır.

Çalışmada laravel, bootsrap, javascript ve solidity ile kullanılabilir, hızlı ve güvenli bir yapı kurmayı hedeflemektedir. Bunların yanında etheryum ağında tutulacak veriler için gerekli olan cüzdan kodu da MetaMask uygulaması üzerinden gerçekleştirilmektedir.

\section{Laravel, Bootstrap ve JS}

Çalışma, web üzerinde işlemlerini gerçekleştirmektedir. Gelişen teknoloji ile kablolardan kurtulan cihazlar hayatımızda fazlasıyla yer almaktadır. Bu teknolojiler bizler için vazgeçilmez bir intiyaç haline gelmeye başlamıştır. Bunu göz önüne alarak çalışmanın hem bilgisayar hem de mobil ortamda sürdürülebilir olması hedeflenmiştir. Bu nedenle HTML-CSS kullanarak görsel deneyim sunan bootstrap ile kullanıcılara responsive bir uygulama geliştirilmiştir. Yazılım geliştirme bakım onarım ve güncelleme süreçlerine sahiptir (Batar ve ark., 2021). Bu teknolojiyi güvenli ve güncellenebilir bir şekilde geliştirmek için laravel temeline sahip bir çaıışma ortaya çıkarılmıştır.

Blok zincir yapısına bağlanmayı sağlayacak web3.js'yi kullanabilmek aynı zamanda kullanıcılara animasyonlar ile daha iyi bir deneyim sunmak için javascript kodlamasından faydalanılmaktadır.

\section{Blok Zincir}

Bloklar ile meydana gelen blok zinciri, şifrelenmiş verileri tutan veri tabanı sistemlerine benzemektedir (Ünal ve Uluyol, 2020). Belki günümüz veri tabanı olarak adlandırılabilir. Fakat tam olarak bir veri tabanı değildir (Nofer ve ark., 2017). Blok zincir birbirlerini takip eden ve her biri bir öncekinin özel verisini tutan bir zincir yapısıdır. En basit blok zincir yapısı Şekil 1'de gösterilmektedir. 


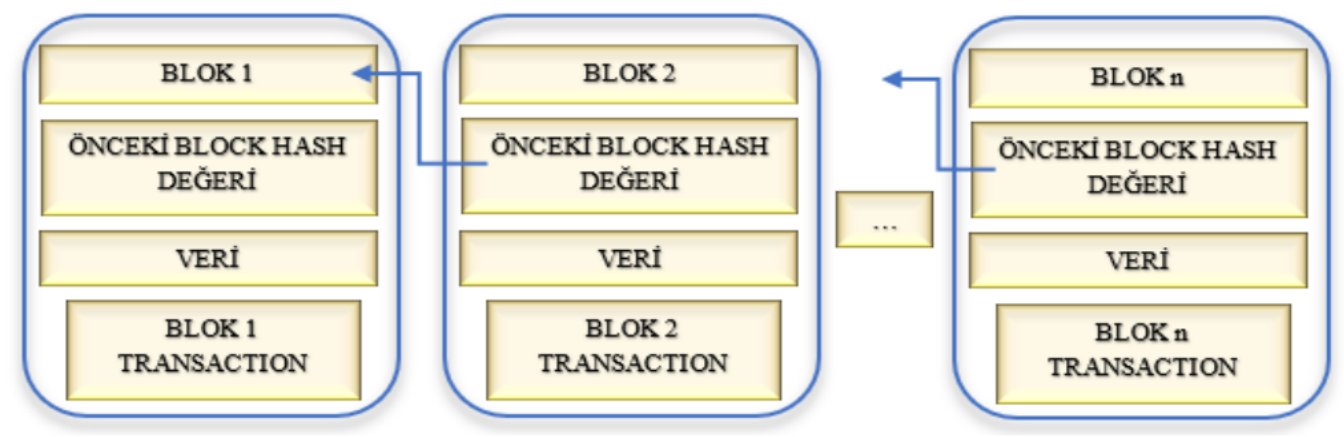

Şekil 1. Blok zincir temel yapısı (Gürfidan ve Akçay, 2020)

S- $\mathrm{CO}_{2}$ Brayton çevrimi ve hava Brayton çevrimlerinde ekserji verimleri incelendiğinde türbin giriş basıncının arttırılması ekserji verimi yükseltmektedir. Ancak sabit basınçta türbin giriş sıcaklıklarının arttıııması ekserji verimini azaltmaktadır. Şekil 4a'da $\mathrm{S}-\mathrm{CO}_{2}$ ve Şekil 4b'de Hava Brayton çevrimlerinde türbin giriş basıncı ile çevrim ekserji verimi değişimi gösterilmiştir. Hava (b) Brayton çevriminde türbin giriş sıcaklığının $600^{\circ} \mathrm{C}$ olduğu değere incelendiğinde maksimum basınç olan $34 \mathrm{MPa}$ türbin giriş basıncında çevrim ekserji verimi \%115,9'a ulaşmaktadır. Bu değer çevrimdeki en yüksek ekserji verim değeridir.

Blok zincir yapısı bağlı listeye benzetilmektedir. Bağlı listeden en büyük farkı bir önceki bağlı olduğu listenin özet şifresini tutmasıdır (Ünsal ve ark., 2018). Tüm zincir yapısı birbirini takip ettiği ve her bir yapı bir önceki yapıya ait anahtar kelimeyi tutuğu için yapıların değiştirilme olasılığı çok azdır. Şekil 2'de blok zincir yapısının en basit hali gösterilmektedir. Fakat tabi ki bu kadar temel bir yapı değildir. Merkezi olan her yapı elinde bulunduğu kişi tarafından değiştirilebilmektedir. Bloklar temelde blok hashi, bir önceki bloğun hashi, zaman damgası ve veri olmak üzere 4 veri tutmaktadır. Bu verilen zincir yapısının kurucunun isteğine göre değişiklik göstermektedir. Veri, zaman damgası alınarak bir şifreleme algoritması kullanmakta ve veriler şifrelenmektedir. Bu şifre bu bloğun hashi sayılmaktadır. Eğer bu blok ilk blok ise buna "Doğum bloğu" denir ve bir önceki blok için oluşturulan hash burada boştur. Bu bloktan sonra oluşan her blok kendinden önceki blok hashini de saklanmaktadır.

Blok zincir yapısının çeşitleri Şekil 2'de gösterilmektedir. Çalışmada Şekil 2'de yer alan sorumluluğun dağıtılmasına benzer bir yapı kullanılmaktadır. Bu yapı ile etheryum ağında bir test ağına katıldık ve bu test ağı içerisinde blok zinciri kurulmuştur. Bu zincire kendi eklemelerimizi yapılmakta ve bu zinciri de test ağına ekliyoruz. Böylelikle çok fazla bilgisayara ulaşan kayıtları daha güvenli bir yapıya sahip olmaktadır. Bu yapı da en az 3 bilgisayara intiyaç duymaktadır. Bunun sebebi herhangi bir verinin değişmesi durumunda yapı en fazla hangi kayıt varsa onu doğru kabul eder. Burada blok zincirin zayıf noktası ortaya çıkar buna \%51 saldırısı denilmektedir. Ağın \%51'ine sahip herkes bu ağı değiştirebilmektedir. \%51 saldırısı için blok zincir güvenlik araştırmacıları, muazzam büyüklükte bir veriye intiyaç duyulduğunu belirterek bu olasılığı inmal etmektedir (Sayeed ve Marco, 2019). Bu yüzden çalışmada etheryum test ağını tercih ederek binlerce bilgisayara kayıt girilmesi sağlanmıştır. Bu da çalışmayı güvenli kılmaktadır.

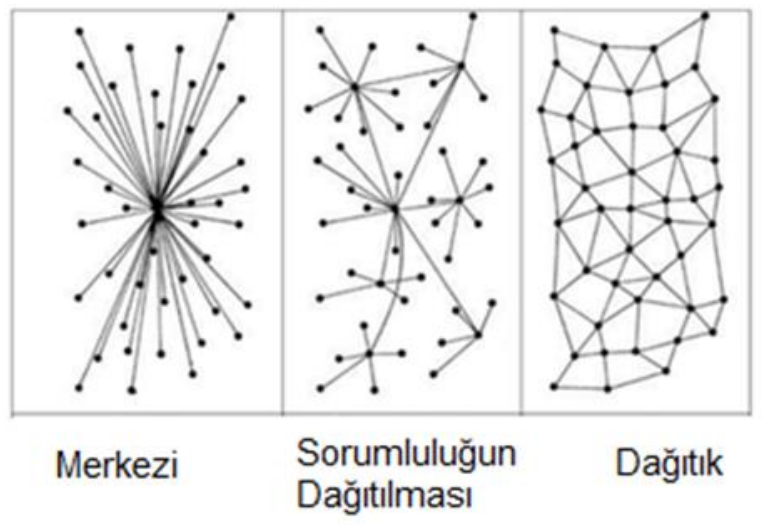

Şekil 2. Blok zincir yapıları (TÜBITAK, 2019)

\section{Web3.js}

Çalışma, blok zincir üzerinde işlem yürütmektedir. Bu ağ üzerinden solidity kullanarak bir kontrat oluşturmaktadır. Web3.js bizim için MetaMask üzerinde yer alan kullanıcı şifremiz ile oluşturduğumuz akıllı kontrata erişim sağlamamızı, akıllı kontrata veri kaydedip veri çekmemize olanak sağlamaktadır. Bu sayede cüzdan ile 
ara yüz arasında bir etkileşim kurulmaktadır (Ranganthan ve ark., 2018).

\section{BULGULAR}

Kullanıcıların anketlerin kontrat üzerinde güvenle saklandığı bir uygulama oluşturulmuştur. İsteyen her kullanıcın çalışma üzerinden kayıt işlemlerini gerçekleştirerek Bunun sayesinde daha kullanışlı hızlı ve güvenli bir yazılım ortaya konulmuştur. Güvenliği ön planda tutan çalışma, kullanıcı deneyimi için hızlı olmayı da hedeflemiştir. Bu hedef doğrultusunda veriler akıllı kontrata güvenle tutuluncaya kadar merkezi bir veri tabanında veriler saklanmaktadır. Akıllı kontrata kayıt işlemi gerçekleştikten sonra isteyen kullanıcı kontrol alanından verilerinin güvenliğini kontrol edebilmektedir. Tüm kullanıcı verileri güvenle blok zincir yapısında saklandığı gibi bu veriler istenildiğinde Tablo 1'de örneklendiği gibi listelenebilir ve anket sonuçlandırılabilir.

Tablo 1. Örnek bir anket çıktısı

\begin{tabular}{|c|c|c|c|c|}
\hline & \multicolumn{3}{|c|}{ Bu çalışmadan nasıl haberiniz oldu? } \\
\cline { 2 - 5 } & $\begin{array}{l}\text { A)Sosyal } \\
\text { Medya }\end{array}$ & $\begin{array}{l}\text { B)Arama } \\
\text { motoru }\end{array}$ & C) Youtube & $\begin{array}{l}\text { D)Arka- } \\
\text { daş }\end{array}$ \\
\hline $\begin{array}{c}\text { Kulla- } \\
\text { nıcı } \\
\text { Sayısı }\end{array}$ & 5 & - & - & 11 \\
\hline
\end{tabular}

\section{Uygulamanın çalıştırılması}

Çalışmanın genel adımlarından bahsedecek olursak. Şekil 3'te gösterildiği gibi bir kullanıcının iki görevi vardır. Bunlardan ilki kullanıcının anket oluşturması bir diğeri ise paylaşmasıdır. Oluşturulan anket diğer kullanıcılar ile paylaşııır ve bu ankete giren kullanıcılar kendi seçeneklerini seçmektedir. Bu seçenekler temelde blok zincir yapısına sahip etheryum ağına kaydedilirken aynı zamanda MySQL veritabanına kaydedilmektedir. Seçiminin hatalı olduğunu düşünen kullanıcı cevabını kontrol edebilmektedir.

Tüm kullanıcıların sisteme erişmesi kolaydır. Herhangi bir abonelik ücreti belirtmeksizin tüm kullanıcılara açık olan sistem belirlenen adrese istenilen platform üzerinden giriş yapabilmektedir. Sisteme giriş yapan kullanıcılar öncelikle sistemin nasıl çalıştığını gösteren bir anlatım ile karşı karşıya geleceklerdir. Tüm platformlar için geçerli olan menü üzerinden sağ üst köşede yer alan Block Survey butonuna tıklayarak çalışmanın giriş ekranına ulaşacaklardır. Sistemin giriş ekranı Şekil 4'te gösterilmektedir.

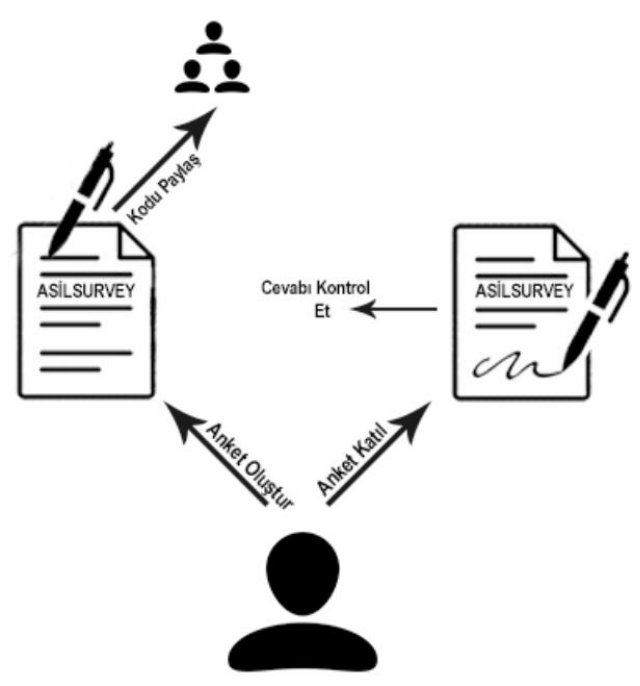

Şekil 3. Uygulamanın çalışması

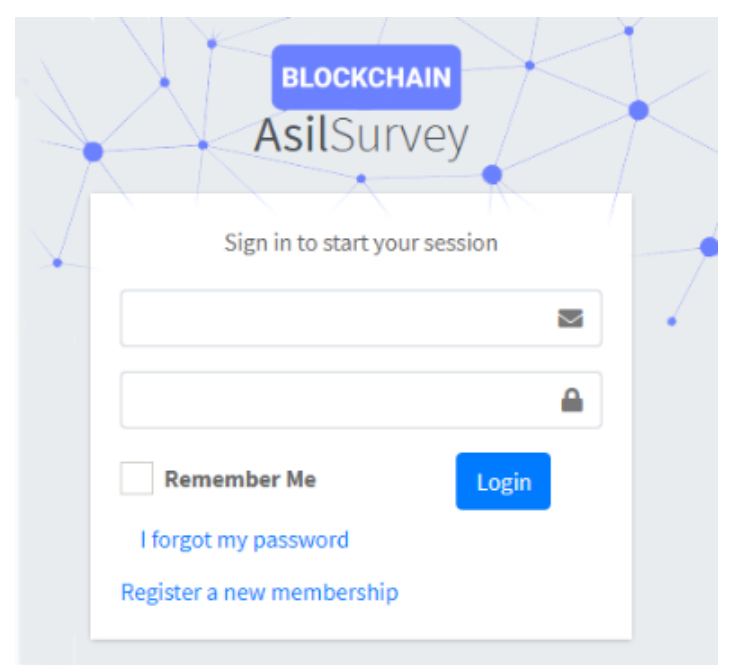

Şekil 4. Sistem giriş ekranı

Şekil 4'te gösterilen ekranda yer alan e-posta ve şifre bilgilerini giren kullanıcılar sisteme erişim hakkına sahip olmaktadır. Giriş ve çalışmanın amacı ve önemi başlıklarında bahsedilen tüm kullanıcılara açık olan sisteme kaydolmak için kaydolma seçeneği kullanılmaktadır. Kaydolmak için istenilen bilgiler ve kayıt ekranı Şekil 5'te gösterilmektedir. 


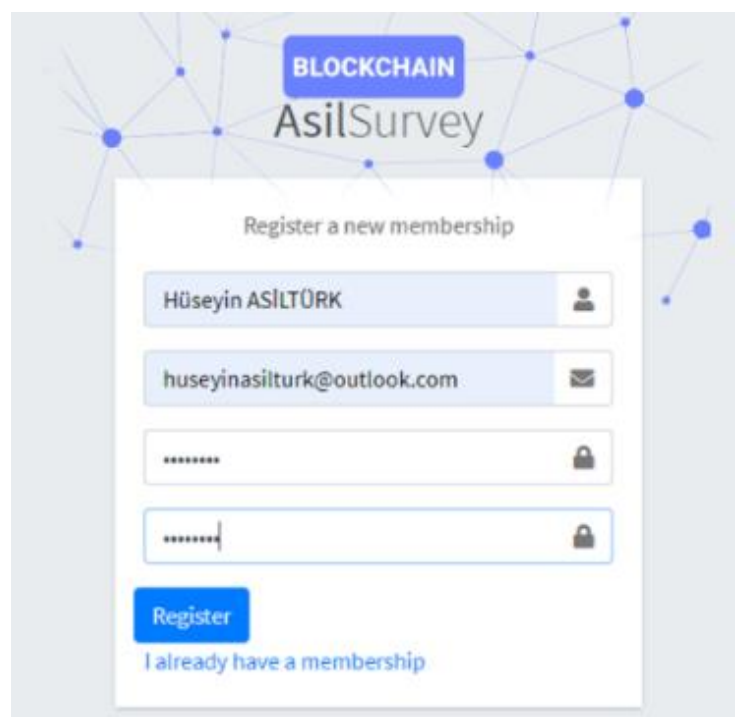

Şekil 5. Kayıt ekranı

Sisteme kaydolan kullanıcılar anket ekle, ankete katıl, cevapları kontrol etme ve profil sayfasına erişim hakkına sahip olacaktır. Sistem üzerinden anket eklemek isteyen kullanıcı menüden anket ekle butonuna tıklamalı ve Şekil 8'te gösterilen alana erişim sağlamalıdır.

Şekil 6'da gösterilen profil bilgileri içerisinde profil anahtarı yer almaktadır. Bu anahtar kullanıcının ankete katılımının ardından veri güvenliğinden endişe duyması durumunda yöneticiye teslim edeceği eşsiz anahtarıdır. Bu anahtarı yönetici etheryum ağında yer alan kayıtlarda kontrol eder ve veriler uyuşmazsa doğrulayıcı olarak etheryum ağında yer alan kontratı kabul eder. Böylelikle verileri saklamak için kullanılan veri tabanı sadece hız ve kullanılabilirlik sağlamak için kullanılmış olur.

Anket oluşturma modülüne giren kullanıcı burada anket sorusu ve seçim içeriği eklemektedir. Şekil 7'de görüldüğü gibi tüm alanlar eklenip anket oluşturulabilmektedir. Altta yer alan ekle butonu ile birden fazla seçim içeriği eklenebilmektedir. Seçim içeriği eklemek için bir sınır bulunmamaktadır. Gönder butonuna basıldıktan sonra kullanıcıya bir anket kodu verilir. Bu anket kodu Şekil 8'de gösterilmektedir. Bu kod ile diğer kullanıcılar tanımlı ankete katılma hakkı kazanmaktadır.

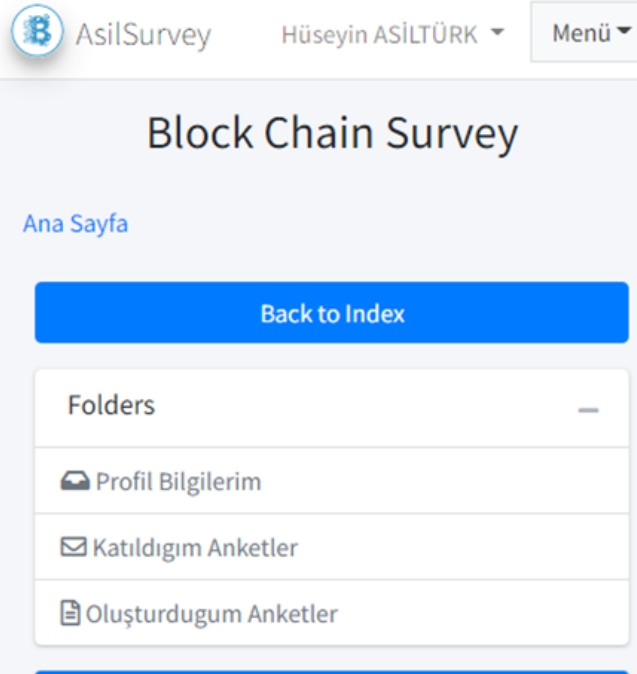

Profil Bilgileri

Profil Anket Key

051202202117534959677003

Şekil 6. Profil bilgileri

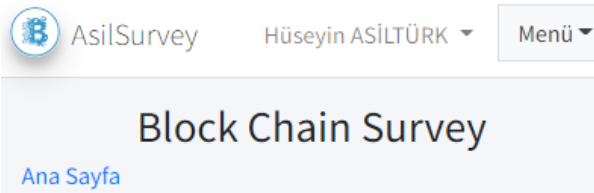

ANKET OLUŞTUR

Anket Sorusu

Atasözüne göre "gönülden de ırak" olan kimdir?

Arabası tamircide olan

Evi uzak olan

Gözden ırak olan

iș yeri karșıda olan

Yeni Seçim Alanı

Ekle

Gönder

Şekil 7. Anket oluşturma ekranı 


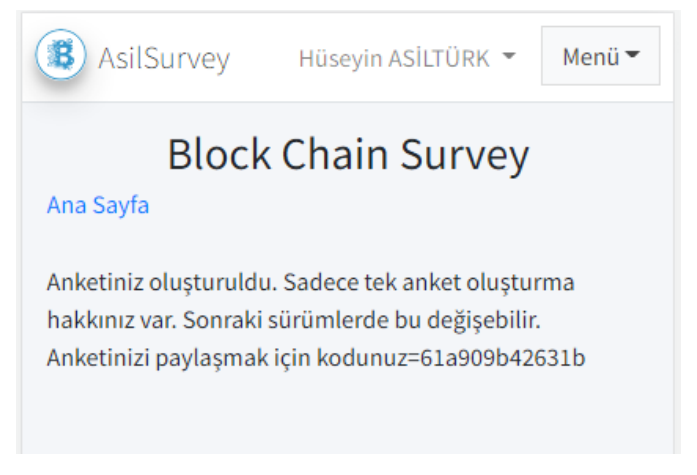

Şekil 8. Anket kodu

Test aşamasında olan çalışma için cüzdan sağlayıcı olan web3.js ile iletişim kurduğumuz metamask eklentisine girerek cüzdan aktif edilmelidir. Bu eklenti sayesinde tarayıcı bir blok zincir tarayıcısına dönüşmektedir (Bhosale, 2019). Bu sayede tüm bilgiler, MySQL dışında güvenli bir yapı olan blok zincir yapısında tutulmaktadır.

Sistem üzerindeki tüm anket cevaplarının veya sorularının güvenle saklanmasını isteyen kullanıcılar MetaMask üzerinden cüzdan bilgilerini girerek sistem ile bağlantılarını tamamlamaları gerekmektedir. Şekil 9 üzerinde MetaMask giriş ekranı gösterilmektedir.

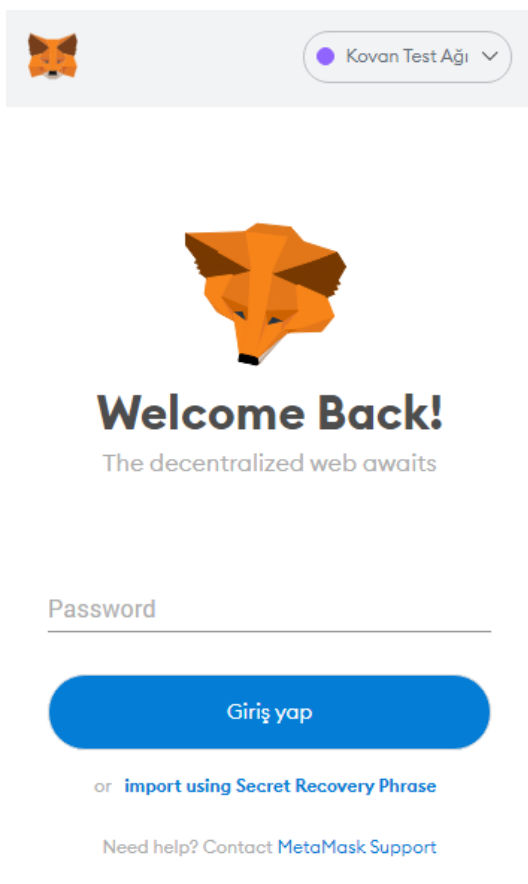

Şekil 9. MetaMask cüzdan sağlayıcısı genel görünümü
Ankete katıl modülüne giren kullanıcı Şekil 10'da yer alan modül ile karşılaşır ve buraya katılmak istediği anket kodunu girmektedir. Bu kod sayesine ekrana geçerli olan anket getirilir.

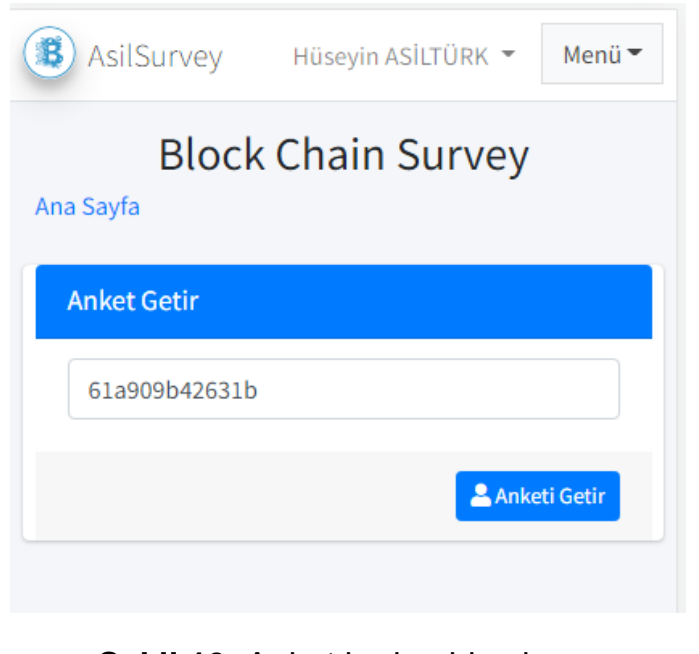

Şekil 10. Anket kodu giriş ekranı

Çalışmada kullanıcı bazlı hazırlanan anketler girilen koda göre ekranda gösterilmektedir. Şekil 11'de bu anketlerden bir tanesi gösterilmektedir. Bu ekrandan kullanıcı istediği cevabı seçerek cevabının ilk olarak sistemdeki veri tabanına kaydını sağlamaktadır. Ardından MetaMask onayı istenmektedir.

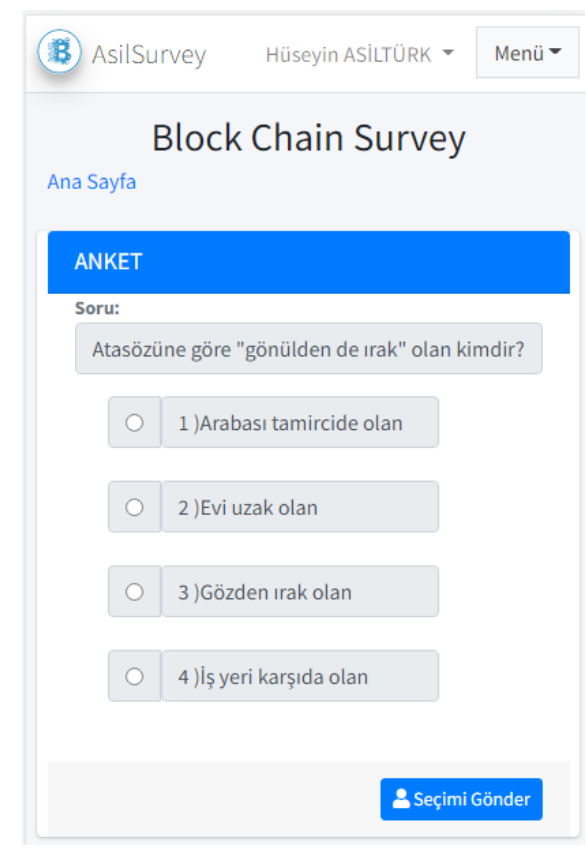

Şekil 11. Anket alanının genel görünümü 
Kullanıcılar cevaplarının güvene alınması için Şekil 12 'de bir örneği gösterilen MetaMask onayını vermektedir. Onayın hemen ardından cevaplar akıllı kontrat üzerinde kayıt için sıraya alınmaktadır. Kullanıcıya işlemin sıraya alındığına dair mesaj iletilmektedir. Kullanıcı bu süreçte çalışma üzerinden beklemeden başka işlemler gerçekleştirebilmektedir.

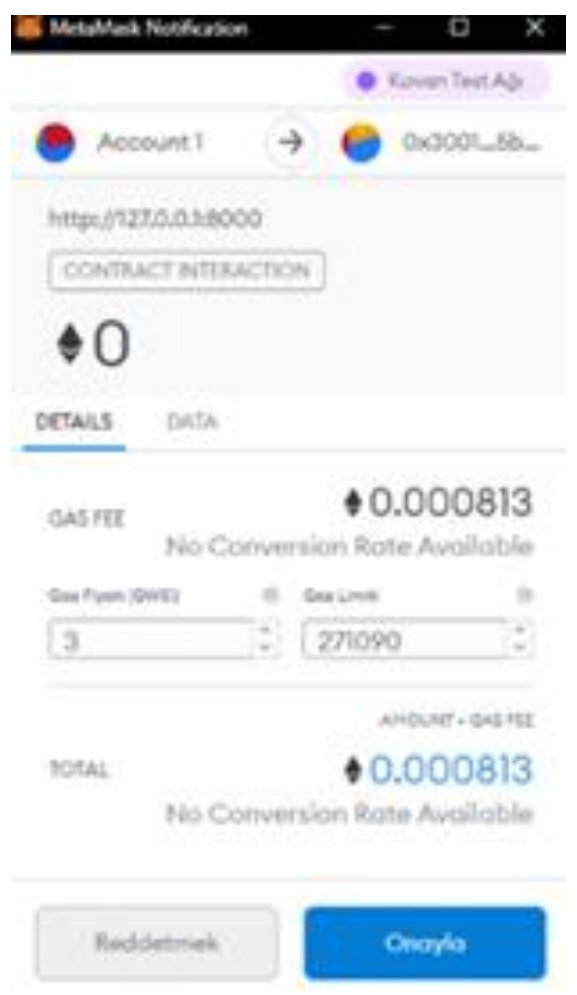

Şekil 12. MetaMask işlem onayı

Şekil 13 ve 14 'de kontrol et butonuna basıldıktan sonra güvenlik sorunu bulunan ve profil sayfasında yer alan profil anahtarını yöneticiye e-posta atması gerektiği uyarıyla karşılamaktadır. Bu uyarı örneği Şekil 13'te gösterilmektedir. Fakat herhangi bir sorun yoksa ve blok zincirdeki kayıt ile veri tabanında yer alan kayıt uyuşuyorsa sorun olmadığına dair mesaj almaktadır. Bu güvenlik mesajı da Şekil 14'te gösterilmektedir. Kontrat üzerinde tüm veriler bir veri saklama yöntemi olan json formatında saklanmaktadır. Bu sayede kontrat ve MySQL üzerinde veri karşılaştırma güvenli ve hızlı bir şekilde yapılabilmektedir.

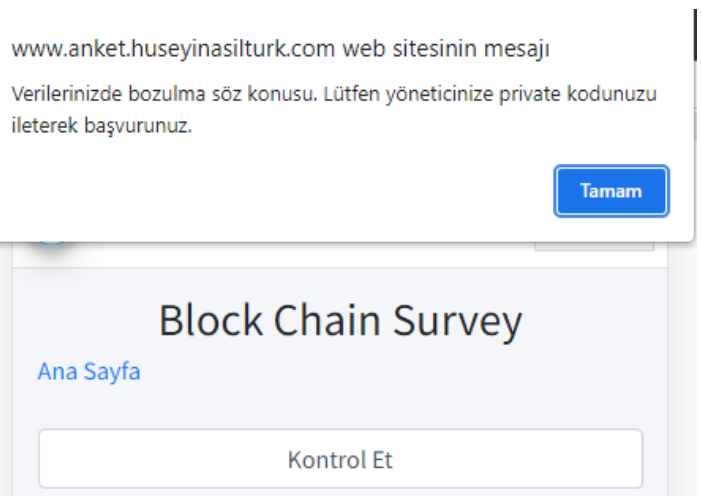

Şekil 13. Verilerin değiştirilmesi

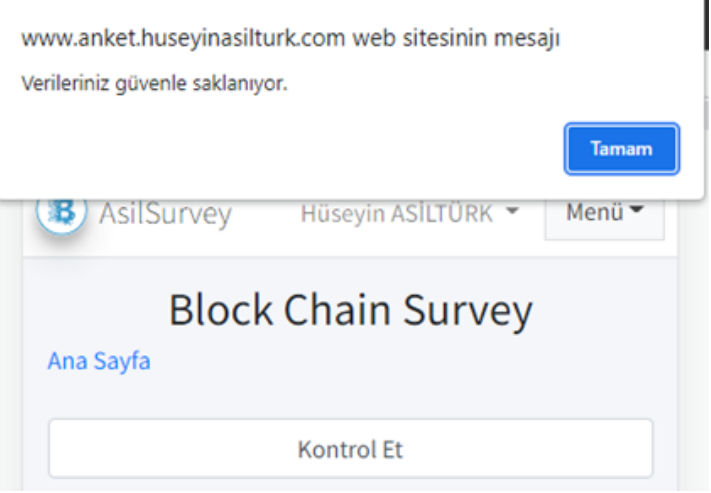

Şekil 14. Verilerin güvende olması

\section{SONUÇ}

Çalışmayla isteyen kullanıcılar anket oluşturabilmekte, ankete katılabilmekte ya da katıldığı anketlerin veri güvenliğini sorgulayabilmektedir. Gelişen teknoloji ve artan veri ile verilerin korunması tüm kurumlar için öncelik haline gelmiştir. Güvenlik endişesi taşıyan kullanıcılar kontrol sağladığında bir sorun ile karşılaşır ise verileri tam güvenlikle etheryum zincirinde tutulduğu için bu veriler doğru veri kabul edilmektedir. Çalışmada kullanıcıların verileri en güvenli şekilde saklanırken kullanıcıya hız ve kullanılabilirlik de sunulmaktadır. Anket şıklarında bir kısıtlama olmaksızın eklenen anketler istenilen sayıda katılımcıya gönderilebilmektedir. Çalışma; mobil, bilgisayar ya da tablet olmak üzere tüm platformlarda çalışmaktadır.

Günümüzde gelişen teknolojiye ayak uyduran çalışma, bu teknolojinin eksik kısımlarını da geçmiş ile birleştirerek tam kullanım sunmayı hedeflemiştir. Günümüz koşullarında bu ve benzeri projelere intiyaç duyulduğu 
görmezden gelinmediği sürece veri güvenliğinin önemli ölçüde korunduğu yeni projelerin çıkması kaçınılmazdır. Tüm bunlarla birlikte anket ve oylama sistemleri içinde uygulama ve benzerlerine intiyaç duyulacağı düşünülmektedir. Gelecekte proje çalışmalarına devam edilecektir. Bu geliştirmeler kullanıcının gizliliği üzerine olduğu gibi kullanılabilirliği güçlendirmeyi de hedeflemektedir. Anonim oy kullanma eklenerek sistemde hem güvenli hem de gizli oylama sistemi getirilecektir. Böylelikle anket çalışması anonim oylama sistemine dönüştürülebilecektir.

\section{KAYNAKLAR}

Batar, M., Birant, K., Isik, A.H. (2021). Yazılım risklerinin doğasına uygun yöntem: Bulanık mantık. Bilgisayar Bilimleri ve Teknolojileri Dergisi, 1(1): 29-35.

Belchior, R., Vasconcelos, A., Guerreiro, S., Correia, M. (2021). A survey on blockchain interoperability: Past, present, and future trends. Association for Computing Machinery Computing Surveys, 54(8): 1-41.

Bhosale, K., Akbarabbas K., Deepak, J., Sankhe, A. (2019). Blockchain based secure data storage. International Research Journal of Engineering and Technology, 6(3): 5058-5061.

Boki, K., Shinoda, S., Ohno, S. (1989). Effects of filtering through bleaching media on decrease of peroxide value of autoxidized soybean fat. Journal of Food Science, 54(6): 1601-1603.

Bulut, R., Kantarcı, A., Keskin, S., Bahtiyar, Ş. (2019). Blockchain-based electronic voting system for elections in Turkey. International Conference on Computer Science and Engineering, 183-188.

Büyükakın, F. (2019). Bankacılık sektörüne blockchain teknolojisinin yansımaları.Internatıonal Congress of Management Economy and Policy, Proceedings Book, 717.

Daramola, O., Thebus, D. (2020). Architecture-centric evaluation of blockchain-based smart contract e-voting for national elections. Informatics. 7(2): 16; DOI: https://doi.org/10.3390/informatics7020016

Gökler, M.E., Turan, Ş. (2020) Covıd-19 pandemisi sürecinde problemli teknoloji kullanımı. Estüdam Halk Sağlığı Dergisi, 5: 108-114.

Gürfidan, R., Akçay, Z. (2020). Blok zincir temelli güvenli elektronik oylama modeli. International Journal of Engineering and Innovative Research, 2(3): 148-155.

Kırbaş, İ. (2018). Blokzinciri teknolojisi ve yakın gelecekteki uygulama alanları. Mehmet Akif Ersoy Üniversitesi Fen Bilimleri Enstitüsü Dergisi, 9(1): 75-82.
Kıyak, Y.S., Coşkun, Ö., Budakoğlu, İ.İ. (2019). Blokzinciri, akıllı kontratlar ve sağlık alanındaki üç uygulama örneği. Hacettepe Sağlık Idaresi Dergisi, 22(2): 457-466.

Kızıltepe, F., Öz, H. (2016). Bitcoin nedir/ne değildir? Vergi Sorunları Dergisi, 39(331): 90-95.

Lin, I.C., Liao T.C. (2017). A survey of blockchain security issues and challenges. International Journal of Network Security, 19(5): 653-659.

Nofer, M., Gomber, P., Hinz, O., Schiereck, D. (2017). Blockchain. Business \& Information Systems Engineering, 59(3): 183-187.

Onay, H., Koç, I.C., Temimhan, K., Erten, M. (2019). Supply chain management using blockchain. EasyChair. 1606

Özdoğan, B., Karğın, S. (2018). Blok zinciri teknolojisinin muhasebe ve finans alanlarına yönelik yansımaları ve beklentiler. Muhasebe ve Finansman Dergisi, (80): 161-176.

Ranganthan, V.P., Dantu, R., Paul, A., Mears, P., Morozov K. (2018). A decentralized marketplace application on the ethereum blockchain. IEEE 4th International Conference on Collaboration and Internet Computing, 90-97.

Ryan, P.Y., Schneider S., Teague, V. (2015). End-to-end Verifiability in voting systems, from theory to practice. Security \& Privacy, 13(3): 59-62.

Sayeed, S., Marco-Gisbert, H. (2019). Assessing blockchain consensus and security mechanisms against the $51 \%$ attack, Applied Sciences, 9(9): 1788.

Tekin, M., Öztürk, D., Bahar, İ. (2020). Akıllı lojistik faaliyetlerinde blokzincir teknolojisi. Kent Akademisi, 13(3): 570583.

Tijan, E., Aksentijević, S., Ivanić, K., Jardas, M. (2019). Blockchain technology implementation in logistics. Sustainability, 11(4): 1185.

Treleaven, P., Brown, R.G., Yang, D. (2017). Blockchain technology in finance. The Institute of Electrical and Electronics Engineers, 50(9): 14-17.

TÜBITAK (2021). Blok Zincir Araştırma Laboratuvarı, 'Blok Zincir Teknolojileri', https://bilgem.tubitak.gov.tr/tr/urunler/blokzincir-arastirma-laboratuvari (Erişim Tarihi: 26.05.2021)

Ünal, G., Uluyol, Ç. (2020). Blok zinciri teknolojisi. Bilişim Teknolojileri Dergisi,12(2): 167-175.

Ünsal E., Kocaoğlu Ö. (2018). Blok zinciri teknolojisi: kullanım alanları, açık noktaları ve gelecek beklentileri. Avrupa Bilim ve Teknoloji Dergisi, (13): 54-64.

Wang, X., Zha, X., Ni, W., Liu, R.P., Guo, Y. J., Niu, X., Zheng, K. (2019). Survey on blockchain for Internet of Things. Computer Communications, 136 (1): 10-29.

Zhang, P., White, J., Schmidt, D.C., Lenz, G. (2017). Applying software patterns to address interoperability in blockchain-based healthcare apps; arXiv:1706.03700 